Supplement to the research article:

\title{
Simulating emission and chemical evolution of coarse sea- salt particles in the Community Multiscale Air Quality (CMAQ) model
}

\author{
J. T. Kelly ${ }^{1, *}$, P. V. Bhave ${ }^{1}$, C. G. Nolte ${ }^{1}$, U. Shankar ${ }^{2}$, and K. M. Foley ${ }^{1}$ \\ ${ }^{1}$ Atmospheric Modeling and Analysis Division, National Exposure Research Laboratory, Office \\ of Research and Development, U.S. Environmental Protection Agency, RTP, NC \\ ${ }^{2}$ Institute for the Environment, University of North Carolina, Chapel Hill, NC \\ *now at: Planning and Technical Support Division, Air Resources Board, California \\ Environmental Protection Agency, Sacramento, CA \\ Correspondence to J. T. Kelly (jkelly@arb.ca.gov)
}


Table S1. Mean observed (summed over all impactor stages) and model-predicted (summed over all modes) inorganic particle concentrations $\left(\mu \mathrm{g} \mathrm{m}^{-3}\right)$ at three sites near Tampa, FL. Note that this table is for CMAQv4.6, CMAQv4.6b, and CMAQv4.6c during 2-15 May 2002, while Table 2 is for CMAQv4.6b and CMAQv4.6c during 2 May-2June 2002.

\begin{tabular}{|c|c|c|c|c|c|c|c|c|c|c|}
\hline Species & $\mathrm{Obs}^{\mathrm{a}}$ & $\operatorname{Mod}_{\mathrm{v} 4.6}{ }^{b}$ & $\operatorname{Mod}_{\mathrm{v} 4.6 \mathrm{~b}}$ & $\operatorname{Mod}_{\mathrm{v} 4.6 \mathrm{c}}$ & $\mathrm{R}_{\mathrm{v} 4.6^{\mathrm{c}}}$ & $\mathrm{R}_{\mathrm{v} 4.6 \mathrm{~b}}$ & $\mathrm{R}_{\mathrm{v} 4.6 \mathrm{c}}$ & $\mathrm{NMB}_{\mathrm{v} 4.6^{\mathrm{d}}}$ & $\mathrm{NMB}_{\mathrm{v} 4.6 \mathrm{~b}}$ & $\mathrm{NMB}_{\mathrm{v} 4.6 \mathrm{c}}$ \\
\hline \multicolumn{11}{|l|}{ Azalea Park } \\
\hline sulfate & 4.46 & 3.34 & 3.42 & 3.53 & 0.21 & 0.19 & 0.18 & -25.1 & -23.3 & -20.7 \\
\hline ammonium & 1.28 & 0.94 & 0.9 & 0.9 & 0.24 & 0.25 & 0.24 & -26.5 & -29.5 & -29.4 \\
\hline nitrate & 2.6 & 0.07 & 0.08 & 0.82 & -0.03 & 0.08 & 0.23 & -97.3 & -97 & -68.5 \\
\hline sodium & 1.93 & 0.25 & 1.15 & 1.56 & -0.33 & -0.1 & -0.09 & -87.2 & -40.4 & -19.1 \\
\hline chloride & 2.19 & 0.42 & 1.99 & 2.24 & 0.19 & 0.06 & -0.04 & -80.9 & -9.2 & 2.4 \\
\hline \multicolumn{11}{|l|}{ Gandy Bridge } \\
\hline sulfate & 4.55 & 4.23 & 4.23 & 4.31 & -0.07 & -0.09 & -0.13 & -7.1 & -6.9 & -5.2 \\
\hline ammonium & 1.44 & 1.12 & 1.12 & 1.12 & -0.05 & -0.04 & -0.09 & -22.1 & -22.4 & -22.1 \\
\hline nitrate & 2.31 & 0.05 & 0.05 & 0.92 & -0.08 & 0.03 & 0.23 & -98 & -98 & -60.3 \\
\hline sodium & 1.77 & 0.32 & 0.59 & 0.86 & -0.54 & -0.31 & 0.07 & -82.2 & -66.7 & -51.3 \\
\hline chloride & 1.89 & 0.54 & 1.01 & 0.96 & -0.32 & -0.01 & 0.22 & -71.3 & -46.6 & -49.2 \\
\hline \multicolumn{11}{|l|}{ Sydney } \\
\hline sulfate & 3.66 & 2.99 & 3.01 & 3.09 & 0.53 & 0.52 & 0.48 & -18.3 & -17.8 & -15.6 \\
\hline ammonium & 1.15 & 1.04 & 1.04 & 1.04 & 0.22 & 0.24 & 0.28 & -9.5 & -9.2 & -9.5 \\
\hline nitrate & 1.96 & 0.29 & 0.29 & 0.84 & 0.35 & 0.35 & 0.57 & -85.4 & -85.1 & -57.3 \\
\hline sodium & 1.32 & 0.2 & 0.3 & 0.51 & 0.56 & 0.19 & -0.12 & -84.6 & -77 & -61.6 \\
\hline chloride & 1.36 & 0.34 & 0.5 & 0.5 & 0.81 & 0.41 & 0.38 & -74.9 & -62.9 & -63.2 \\
\hline \multicolumn{11}{|l|}{ All Sites } \\
\hline sulfate & 4.23 & 3.51 & 3.54 & 3.64 & 0.22 & 0.22 & 0.2 & -17.2 & -16.3 & -14.1 \\
\hline ammonium & 1.29 & 1.03 & 1.01 & 1.01 & 0.17 & 0.18 & 0.18 & -20.2 & -21.4 & -21.3 \\
\hline nitrate & 2.31 & 0.13 & 0.14 & 0.86 & -0.11 & -0.08 & 0.24 & -94.3 & -94.1 & -63 \\
\hline sodium & 1.69 & 0.25 & 0.71 & 1.01 & 0.14 & 0.28 & 0.27 & -84.9 & -57.9 & -40 \\
\hline chloride & 1.84 & 0.43 & 1.22 & 1.3 & 0.33 & 0.4 & 0.34 & -76.4 & -33.6 & -29.3 \\
\hline
\end{tabular}

${ }^{\mathrm{a}}$ Observed mean concentration $\left(\mu \mathrm{g} \mathrm{m}^{-3}\right)$

${ }^{b}$ Modeled mean concentration $\left(\mu \mathrm{g} \mathrm{m}^{-3}\right)$ for CMAQv4.6

'Pearson correlation coefficient for CMAQv4.6 predictions

${ }^{\mathrm{d}}$ Normalized mean bias (\%) for CMAQv4.6 predictions; $N M B=\frac{\sum C_{\text {mod }}-C_{o b s}}{\sum C_{o b s}} \times 100 \%$, where $C$ is concentration 


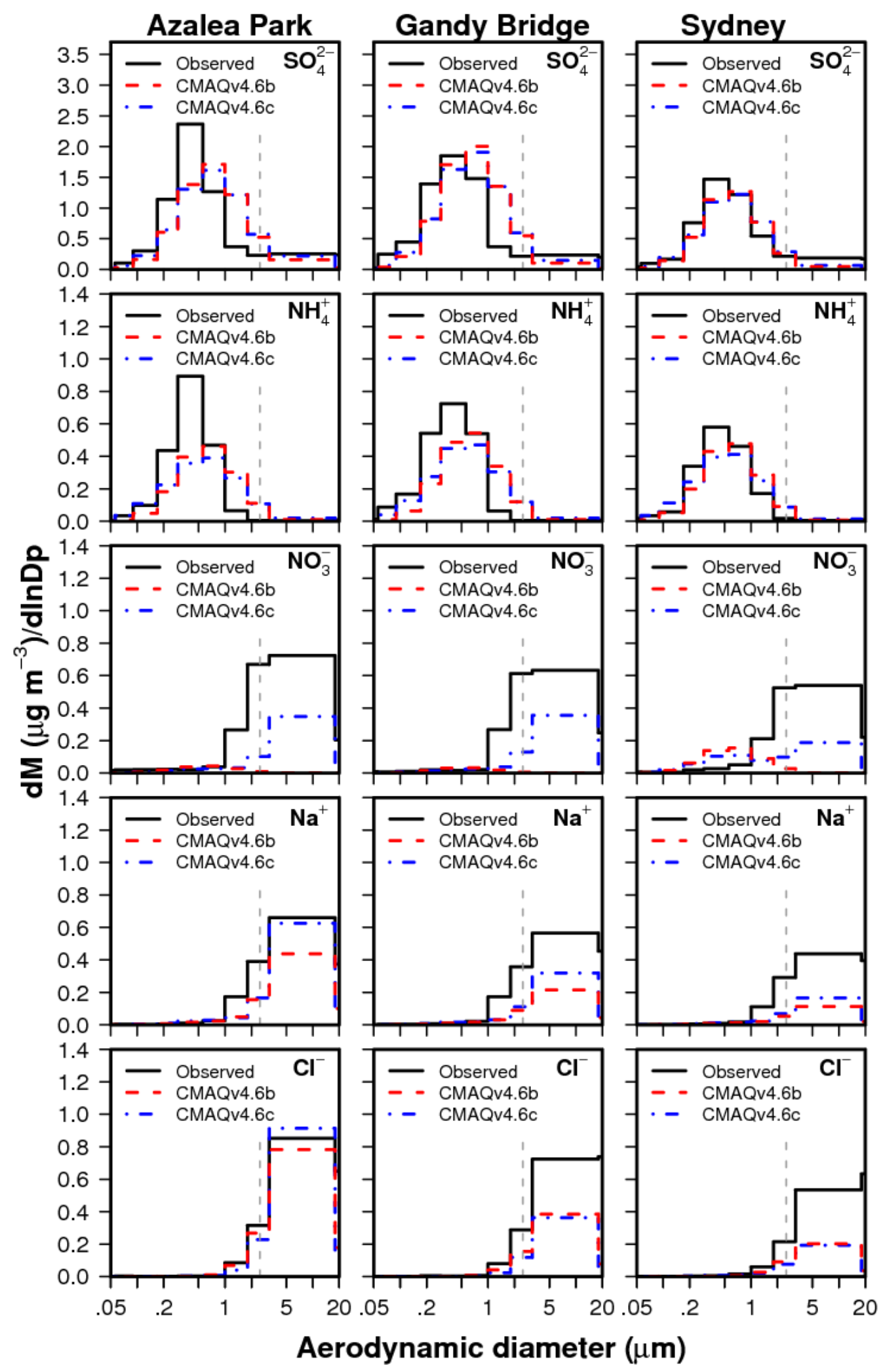

Fig. S1. Same as Fig.5 but with modeled distributions mapped to bins by integrating over relevant diameter ranges. 


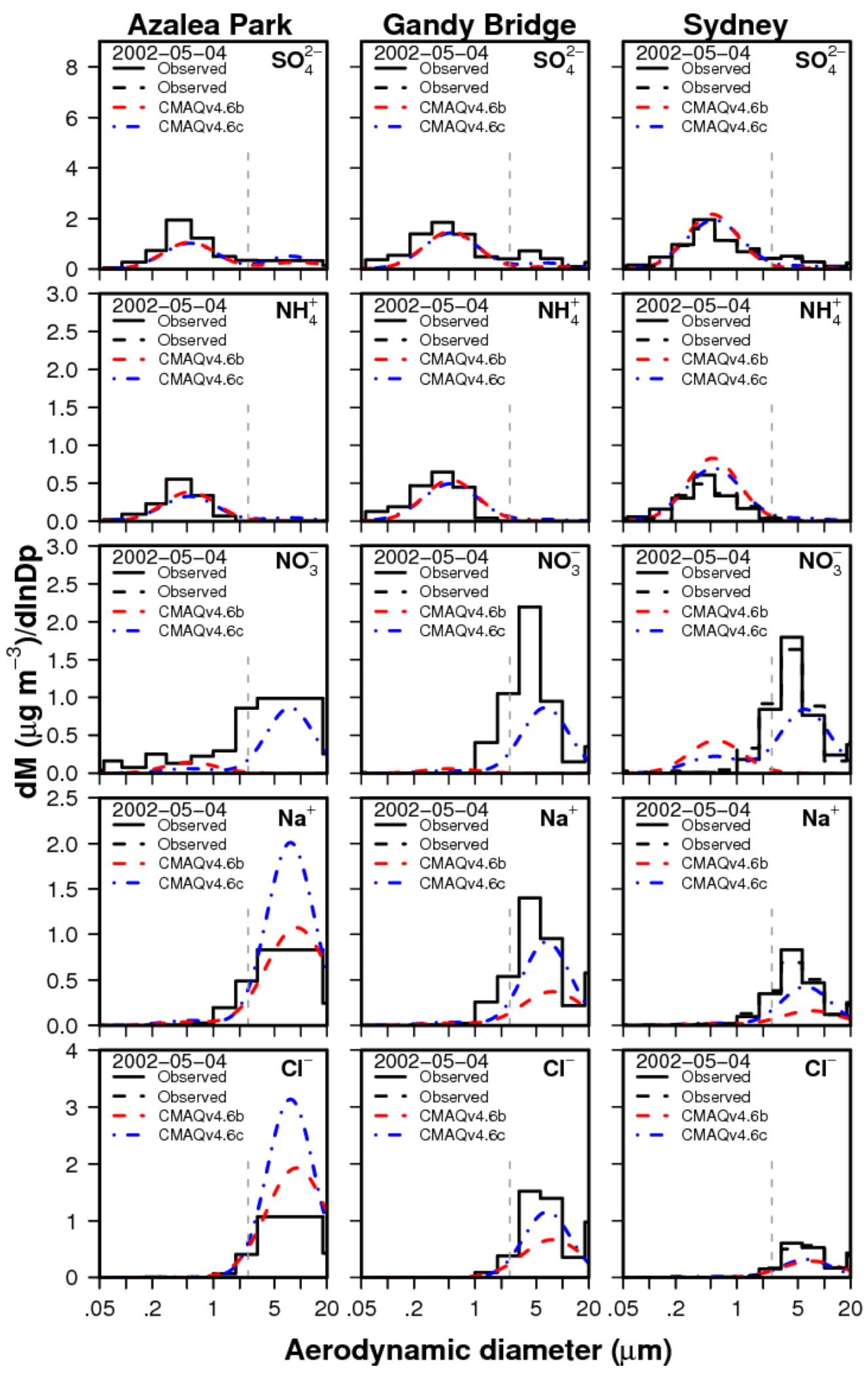

Fig. S2. Observed and predicted size distributions of inorganic particle components at three Tampa-area sites averaged over a 23-h period on 4 May 2002. 


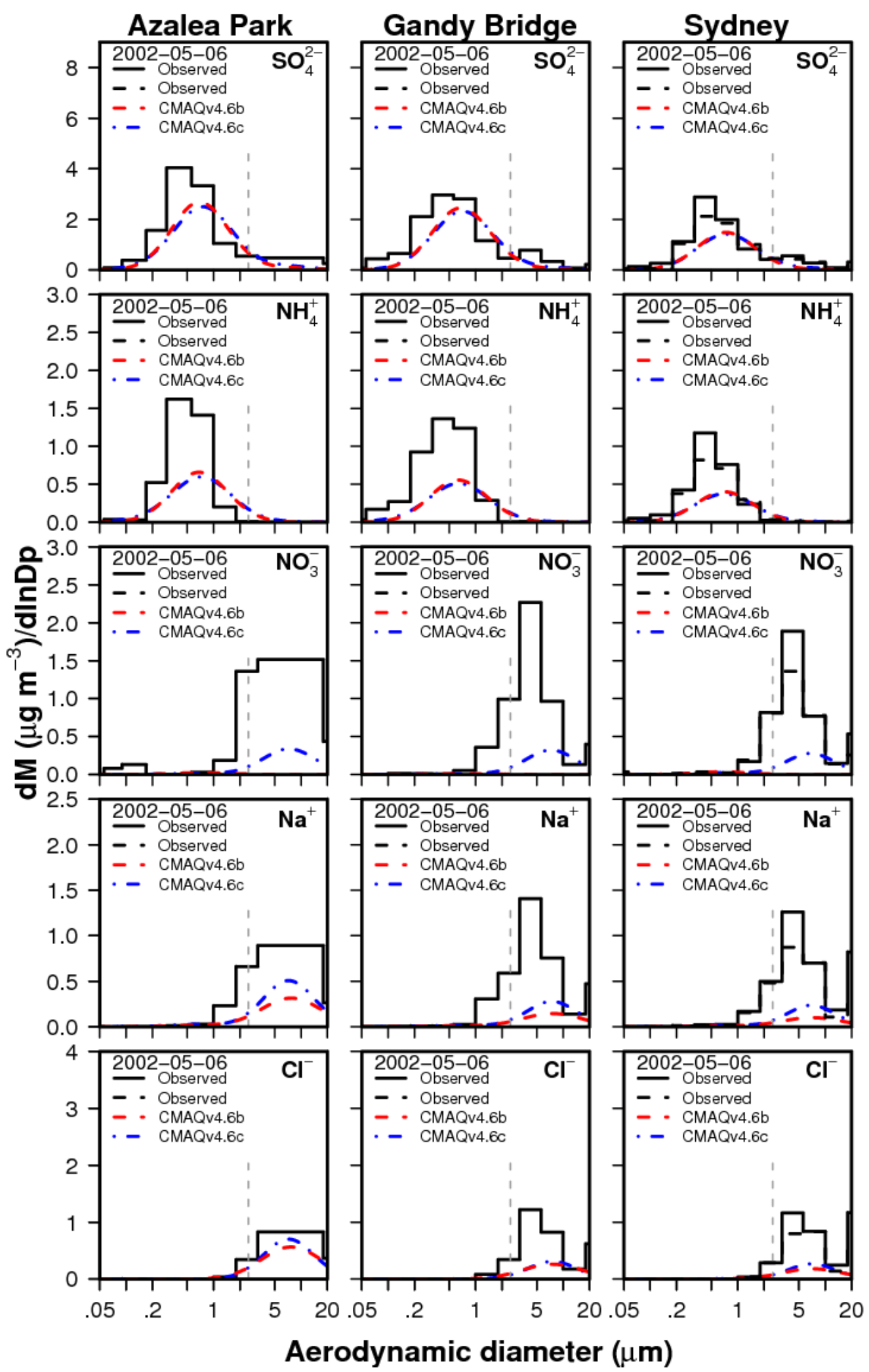

Fig. S3. Observed and predicted size distributions of inorganic particle components at three Tampa-area sites averaged over a 23-h period on 6 May 2002. 


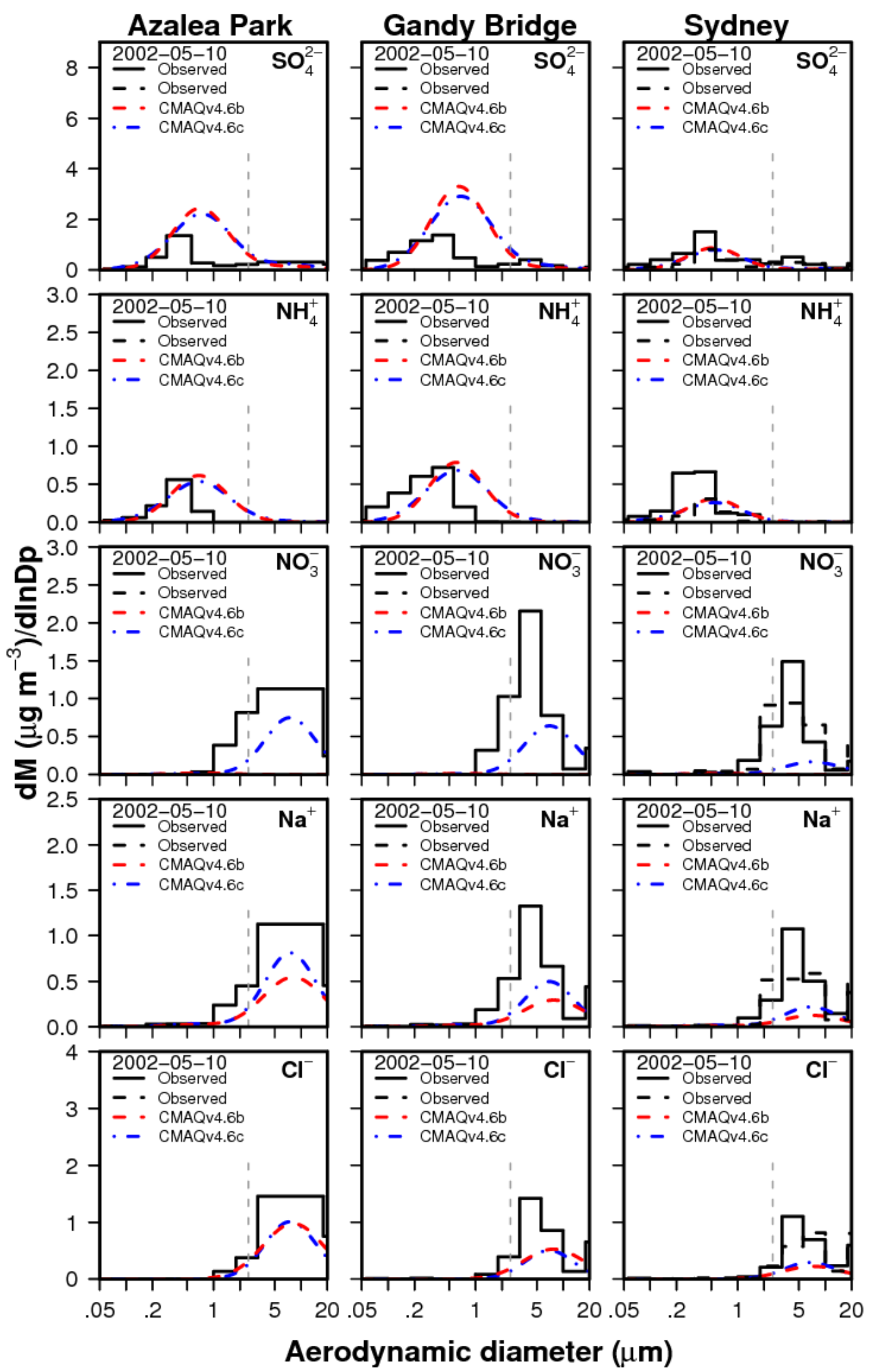

Fig. S4. Observed and predicted size distributions of inorganic particle components at three Tampa-area sites averaged over a 23-h period on 10 May 2002. 


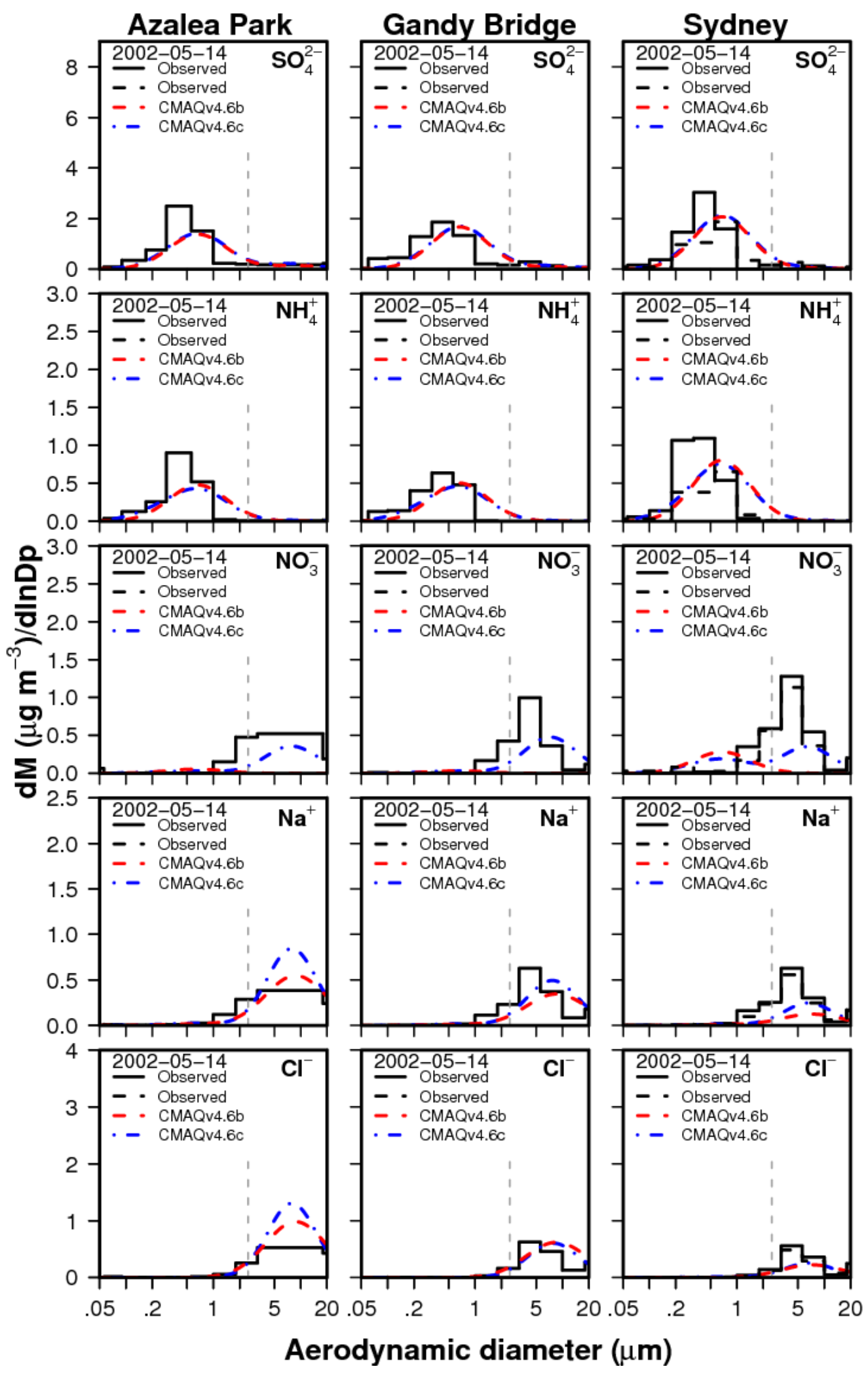

Fig. S5. Observed and predicted size distributions of inorganic particle components at three Tampa-area sites averaged over a 23-h period on 14 May 2002. 


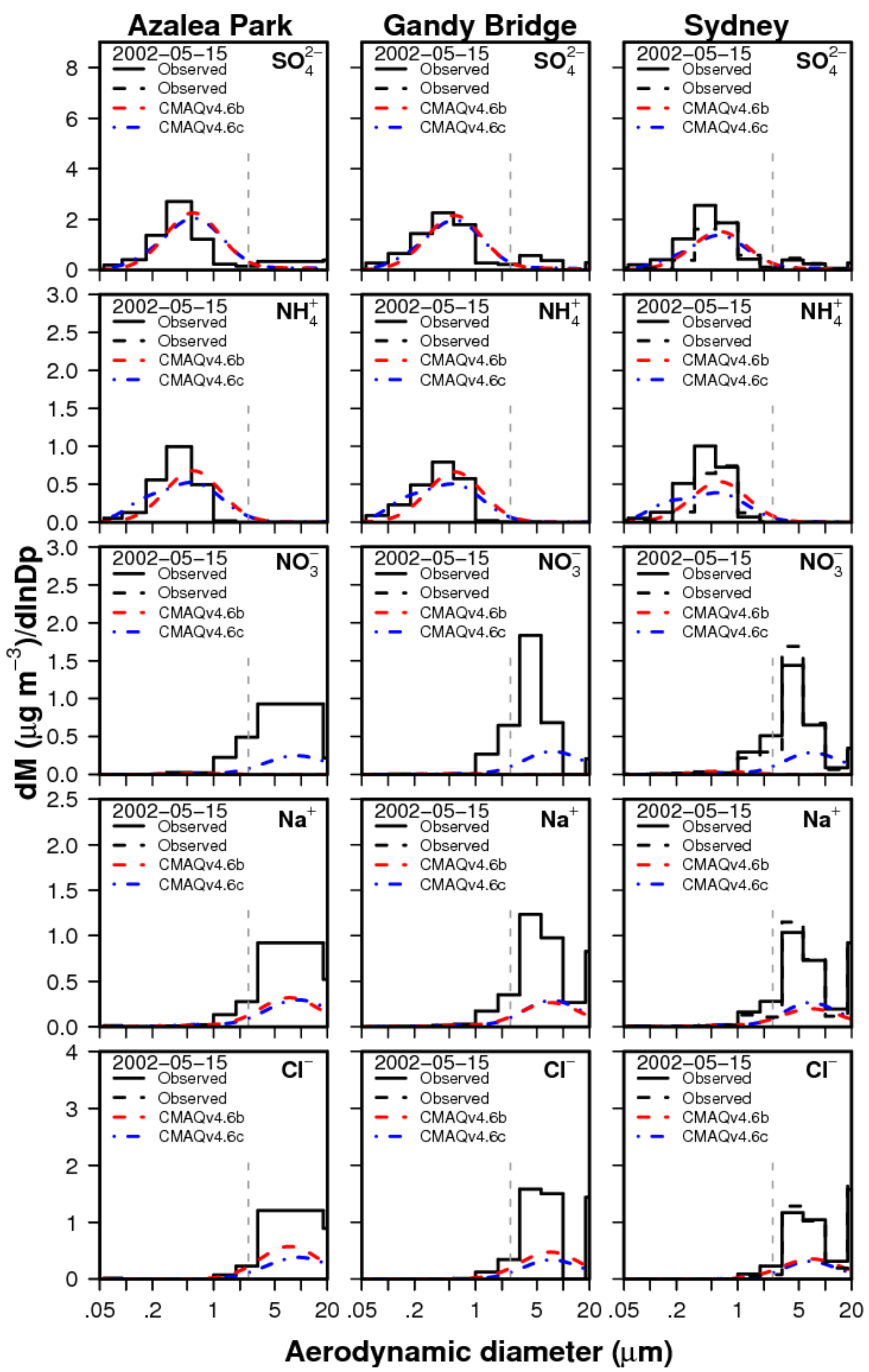

Fig. S6. Observed and predicted size distributions of inorganic particle components at three Tampa-area sites averaged over a 23-h period on 15 May 2002. 


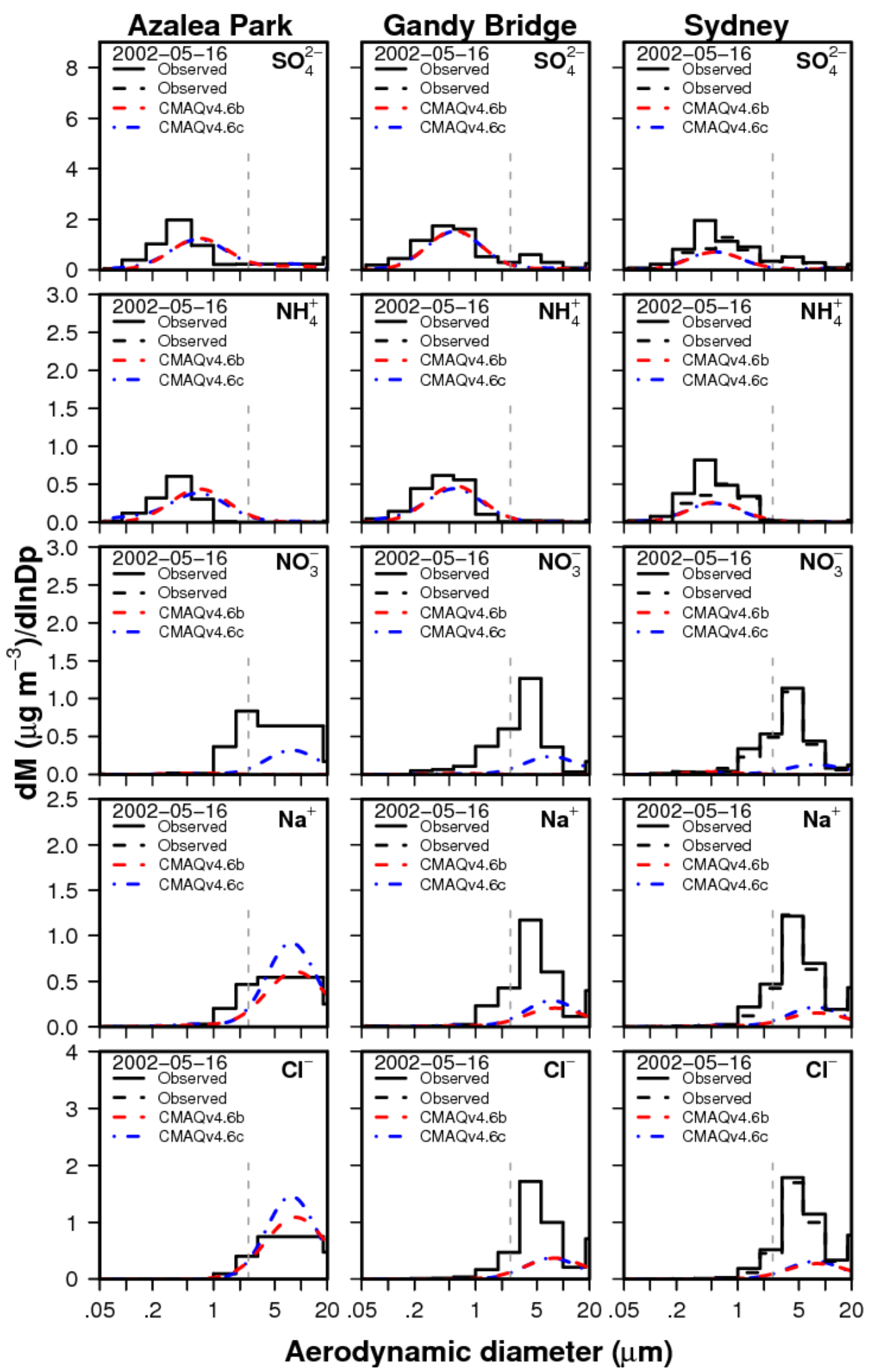

Fig. S7. Observed and predicted size distributions of inorganic particle components at three Tampa-area sites averaged over a 23-h period on 16 May 2002. 


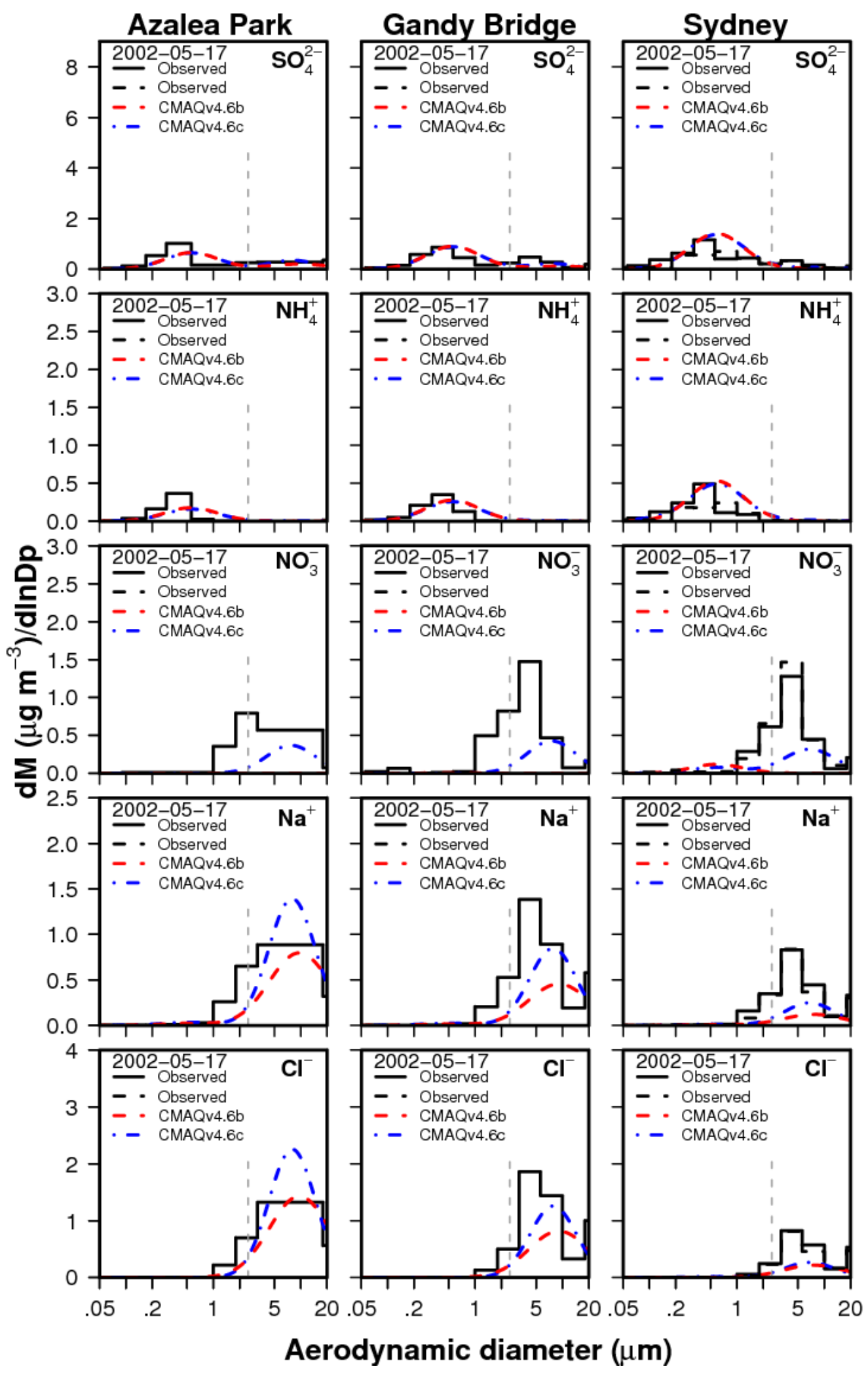

Fig. S8. Observed and predicted size distributions of inorganic particle components at three Tampa-area sites averaged over a 23-h period on 17 May 2002. 


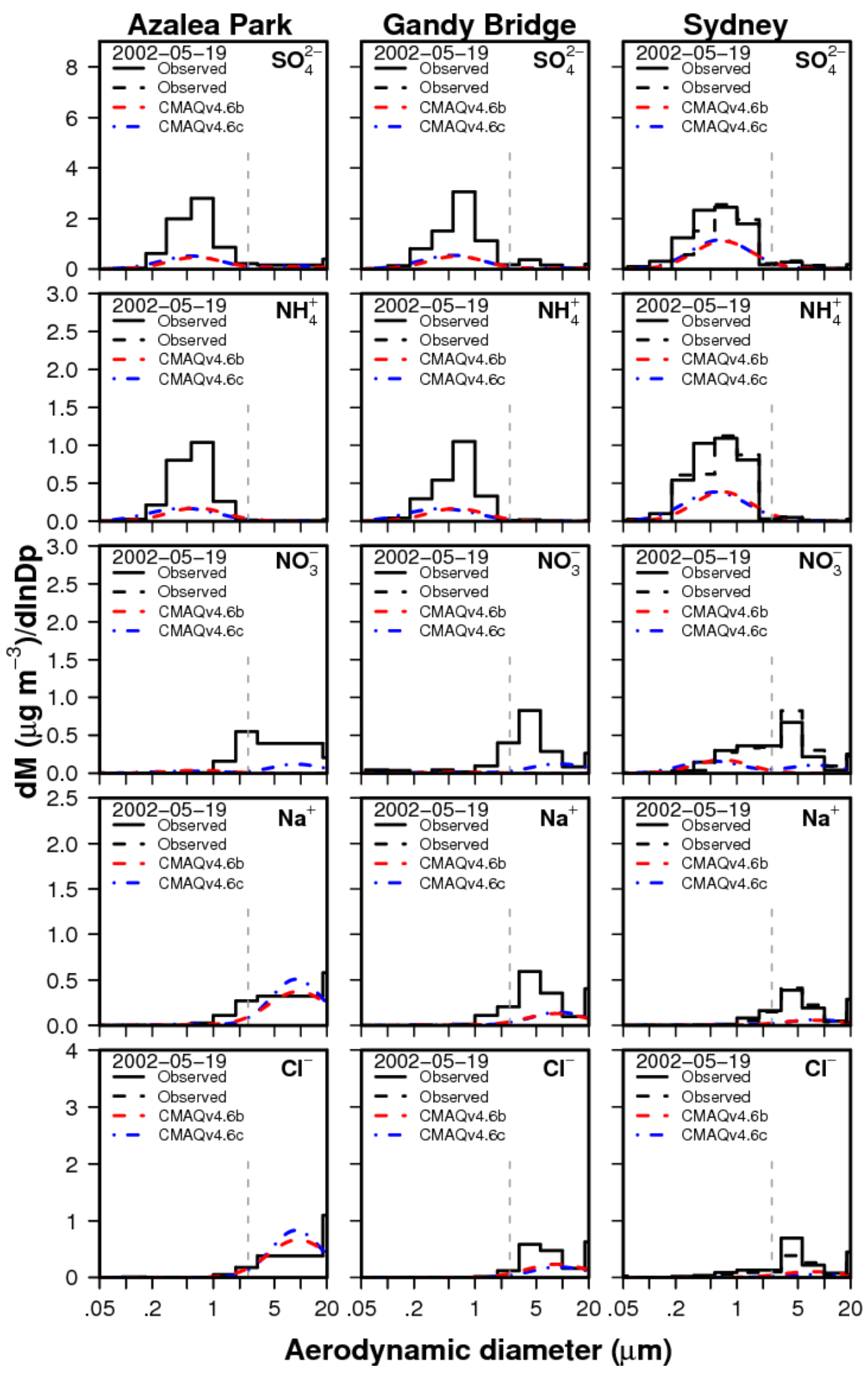

Fig. S9. Observed and predicted size distributions of inorganic particle components at three Tampa-area sites averaged over a 23-h period on 19 May 2002. 


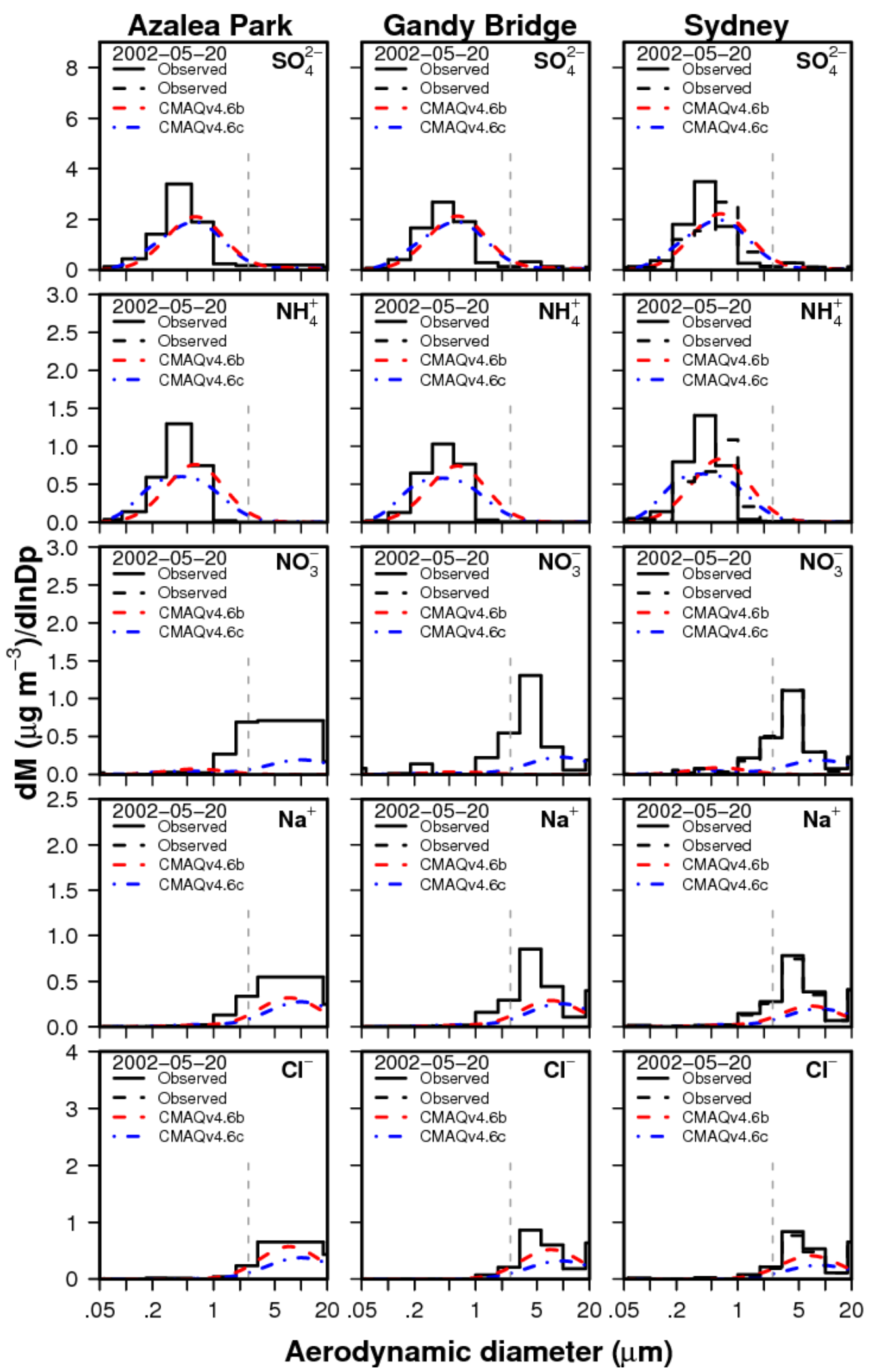

Fig. S10. Observed and predicted size distributions of inorganic particle components at three Tampa-area sites averaged over a 23-h period on 20 May 2002. 


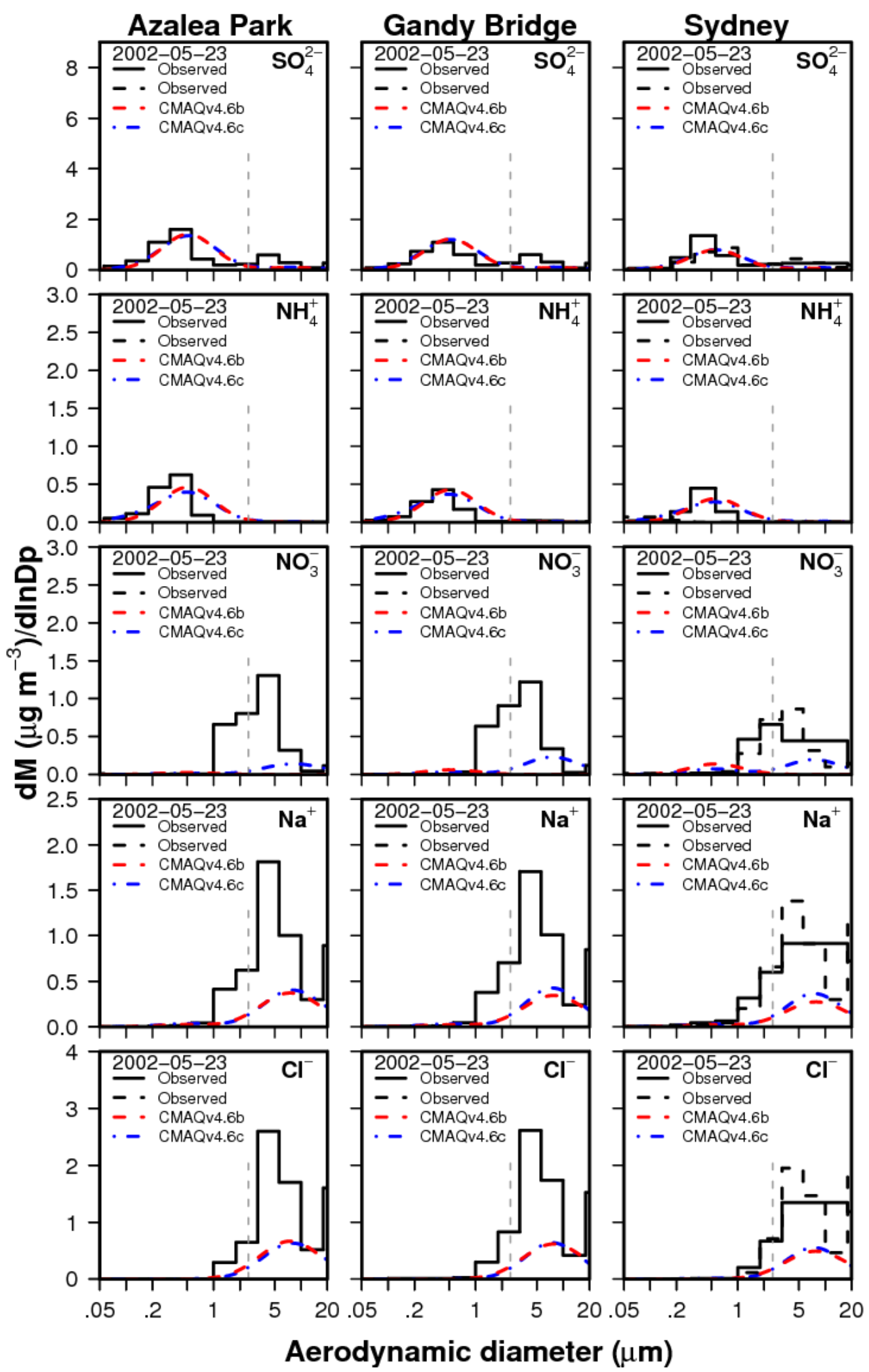

Fig. S11. Observed and predicted size distributions of inorganic particle components at three Tampa-area sites averaged over a 23-h period on 23 May 2002. 


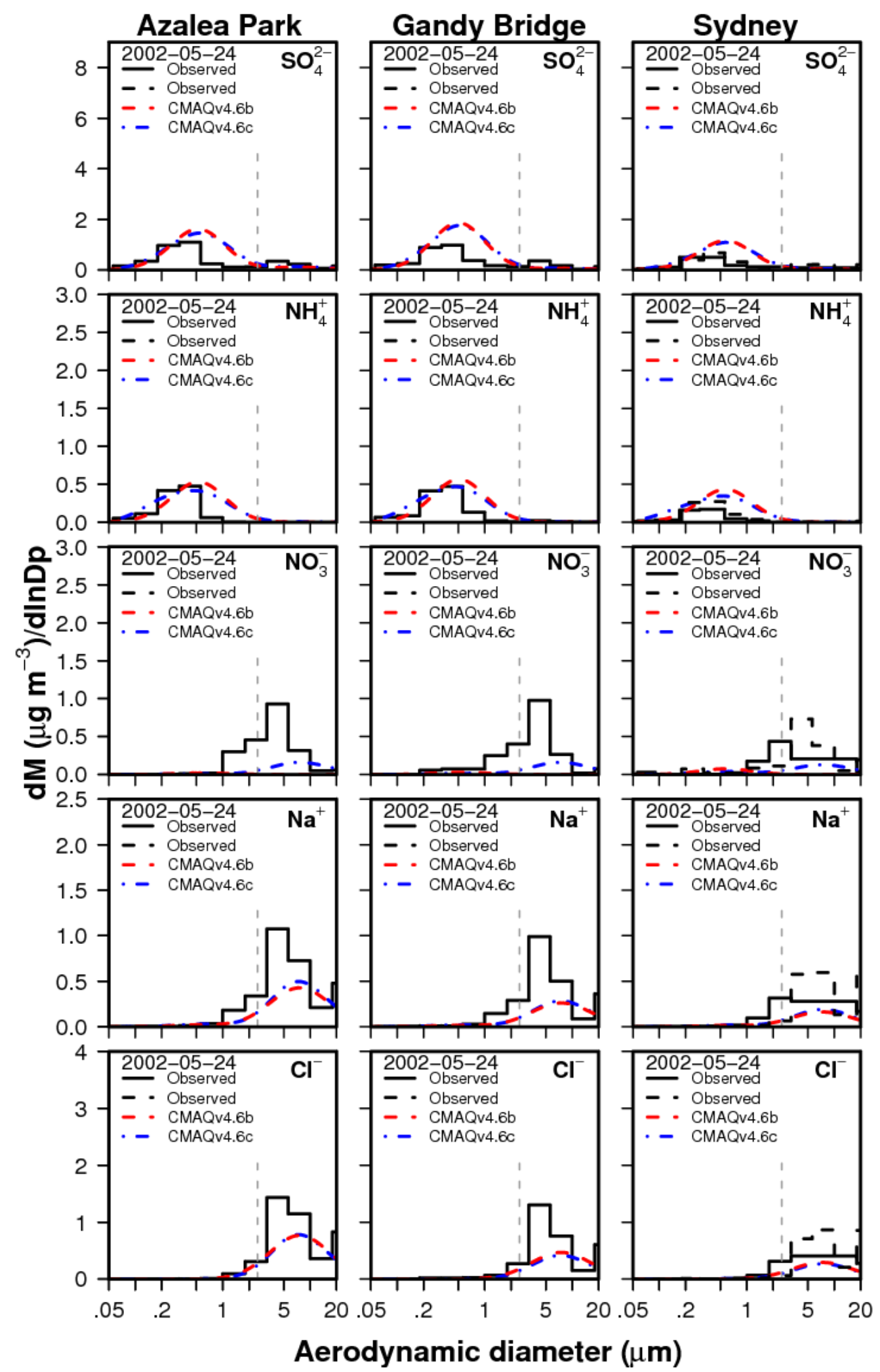

Fig. S12. Observed and predicted size distributions of inorganic particle components at three Tampa-area sites averaged over a 23-h period on 24 May 2002. 


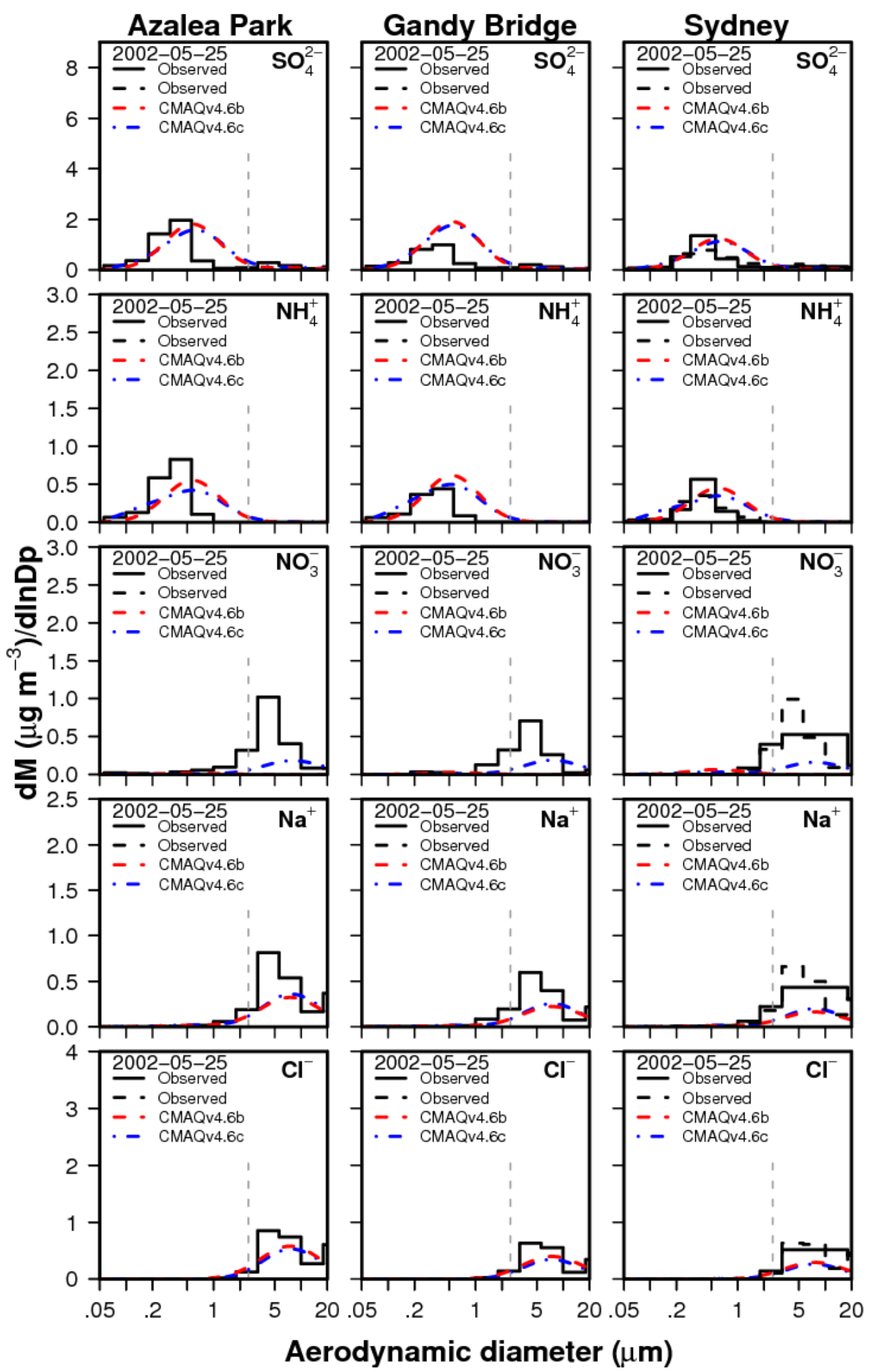

Fig. S13. Observed and predicted size distributions of inorganic particle components at three Tampa-area sites averaged over a 23-h period on 25 May 2002. 


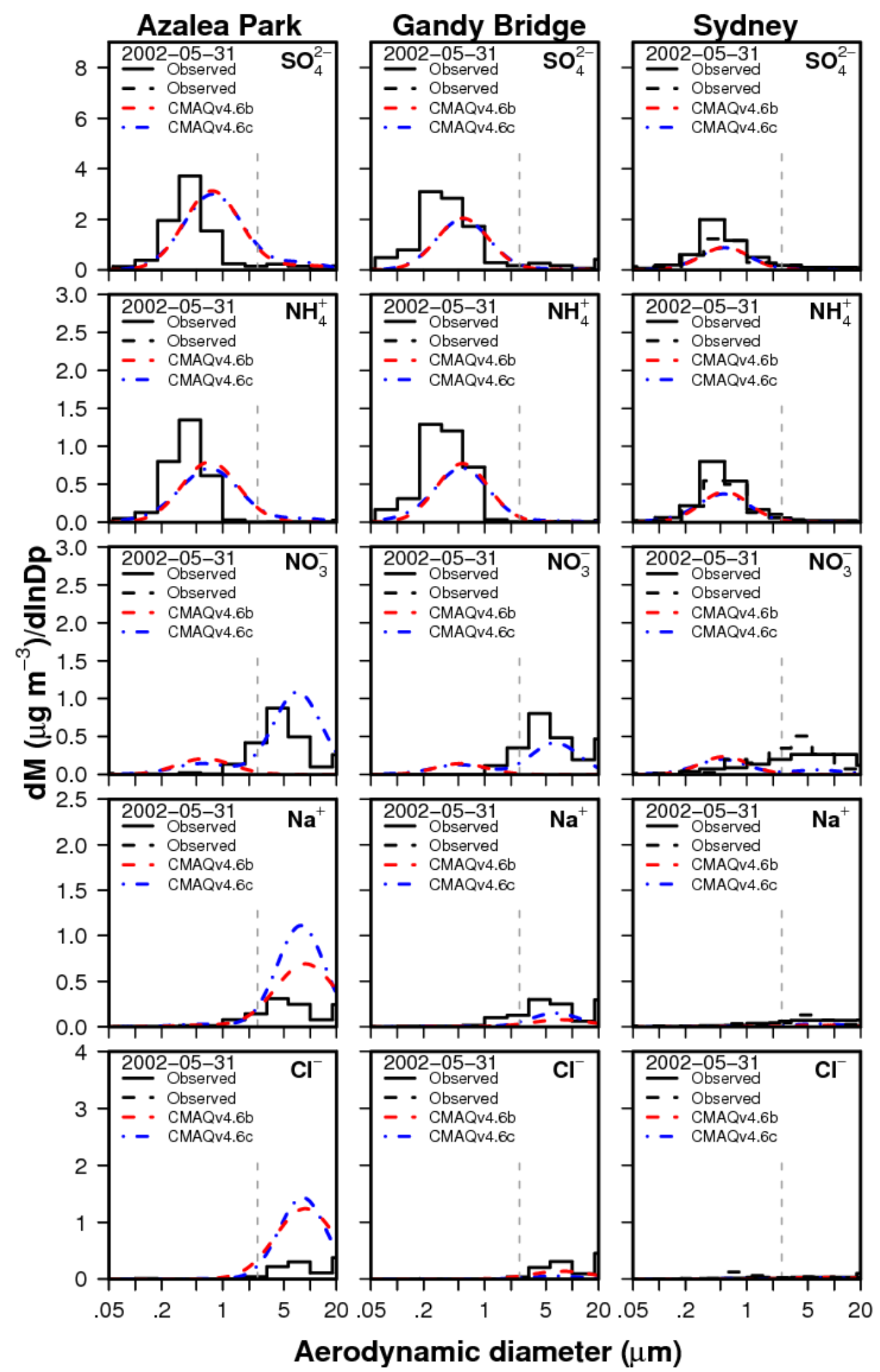

Fig. S14. Observed and predicted size distributions of inorganic particle components at three Tampa-area sites averaged over a 23-h period on 31 May 2002. 


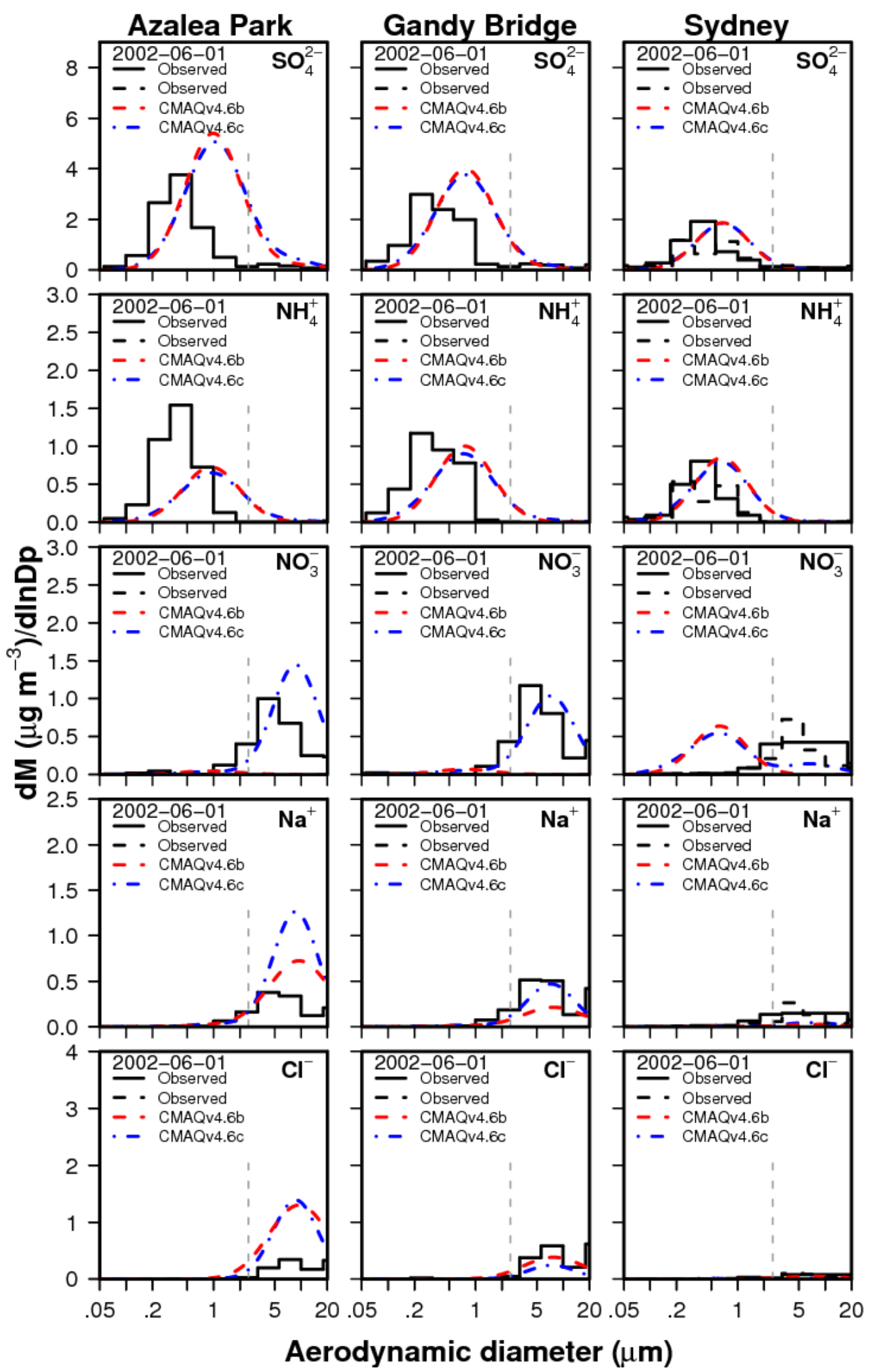

Fig. S15. Observed and predicted size distributions of inorganic particle components at three Tampa-area sites averaged over a 23-h period on 1 June 2002. 
$\mathrm{HNO}_{3}$ Sydney, FL
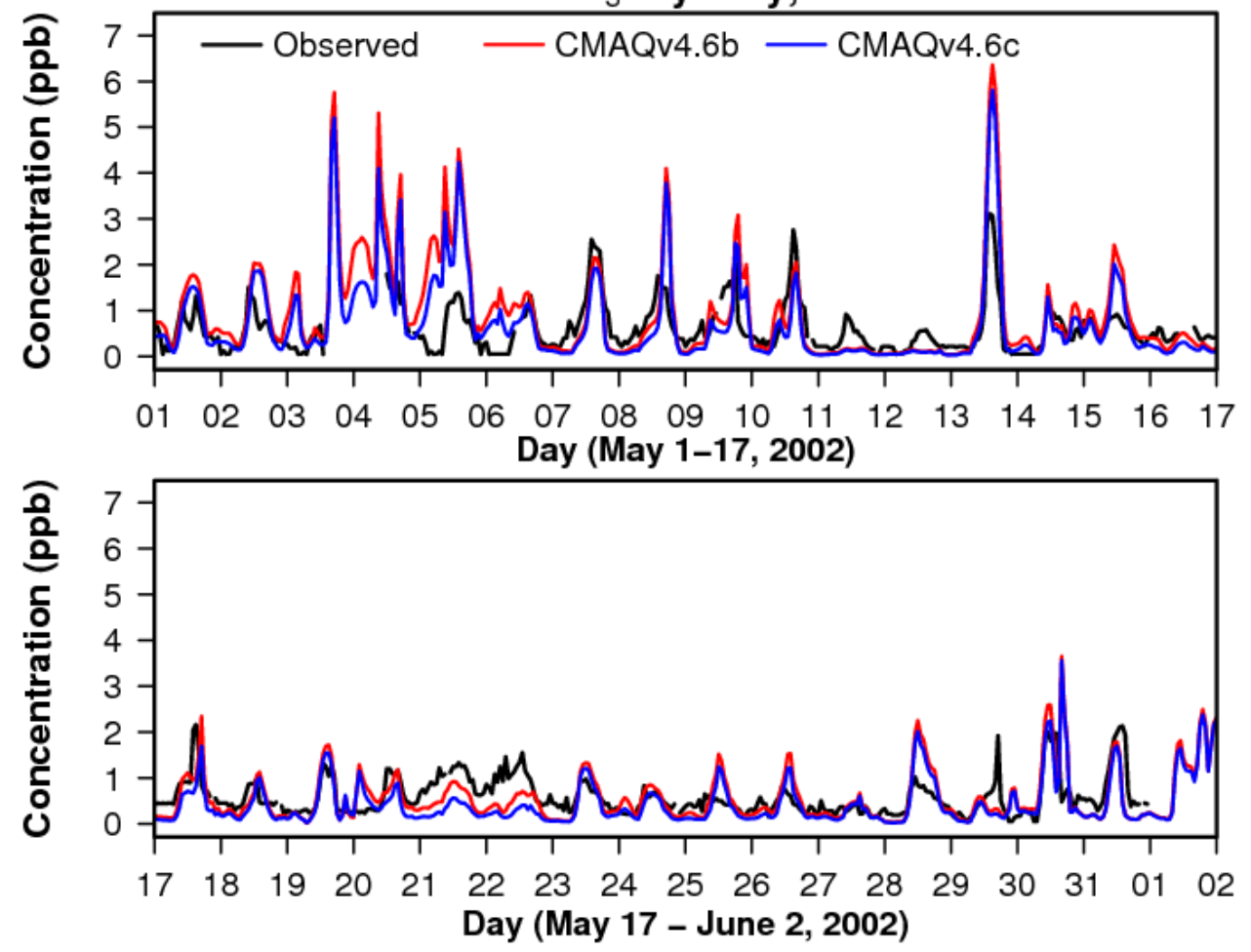

Fig. S16. Time series of observed and modeled nitric acid concentration at the Sydney, FL site from 1 May - 2 June 2002. Tick marks represent 0000 local standard time on each day. 


\section{HCl Sydney, FL}
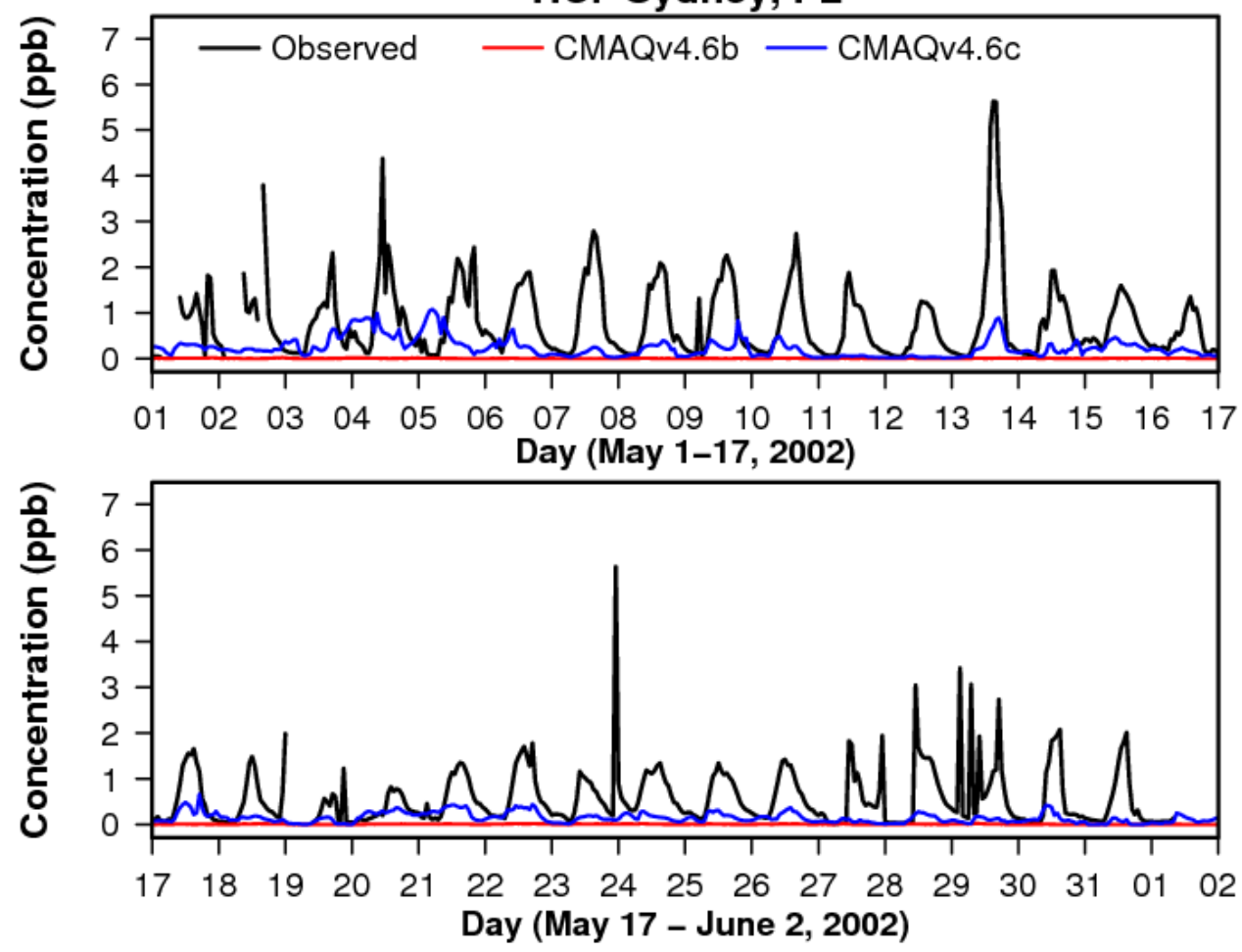

Fig. S17. Time series of observed and modeled hydrochloric acid concentration at the Sydney, FL site from 1 May - 2 June 2002. Tick marks represent 0000 local standard time on each day. 


\section{Open-Ocean and Surf-Zone Grid-Cell Allocation}

In CMAQ, sea-salt emissions are calculated using a gridded file (i.e., OCEAN_1 file) that contains values for the fraction of each cell classified as open-ocean and coastal surf zone. The OCEAN_1 file created for our domain is based on shoreline data of the NOAA Office of Coastal Survey (i.e., the U.S. Seamless Merged Mean High Water Vector Shoreline data). These shoreline data were processed into a shapefile and imported into Geographic Information System (GIS) software (Arclnfo, www.esri.com). A 250-m tolerance was used in Arclnfo to remove vertices and smooth arcs in the shapefile and to ensure acceptable surf-zone classification in areas with complex shorelines. Shoreline arcs were classified as surf-zone or non-surf-zone based on the local coastal features. The shoreline of the bay near the Gandy Bridge site was classified non-surf zone, as were other bays, river inlets, and shorelines protected by barrier islands. The Spatial Allocator tool (documentation and code for the Spatial Allocator are available from http://www.cmascenter.org/) was used to convert data from the GIS-based shapefile into the gridded OCEAN_1 file used in the CMAQ simulations. Instructions on using the Spatial Allocator to compute the grid-cell fraction covered by land, open-ocean, and coastal surf zone are available in Section 7.1.6 of the following: http://www.ie.unc.edu/cempd/projects/mims/spatial/alloc.html. The surf-zone fraction of a grid cell was computed here assuming a 50 -m-wide surf zone adjacent to shoreline arcs with a surf-zone classification. 


\section{Additional Details on Coarse Particle Modeling in CMAQv4.7 (from Release Notes)}

In previous versions of CMAQ, coarse-mode particles were assumed to be dry and inert, and components in the coarse mode could not evaporate or condense. This approach does not allow important aerosol processes, such as replacement of chloride by nitrate in mixed marine/urban air masses, to be simulated. In CMAQ v4.7, the code has been updated to allow semi-volatile aerosol components to condense and evaporate from the coarse mode and nonvolatile sulfate to condense on the coarse mode. Since coarse-particle components are often not in equilibrium with the gas phase, dynamic mass transfer is simulated for the coarse mode (whereas the fine modes are equilibrated instantaneously with the gas phase). This treatment can be found in the new VOLINORG subroutine, which is embedded in the aero_subs.f subprogram.

In coastal regions, significant emissions of sea salt originate from wave-breaking in the surf zone. Previous versions of CMAQ did not account for this process. In CMAQ v4.7, surf-zone emissions are computed in the ssemis.F subprogram by assuming that the surf zone is covered entirely by whitecaps (i.e., WCAP $=1$ ) and that the size distribution of sea salt emitted from the surf zone is identical to that emitted from the open ocean.

The computational efficiency of the CMAQ aerosol module is governed largely by the number of calls to ISORROPIA. In previous versions of CMAQ, only one ISORROPIA call per model time step was required to equilibrate the fine-particle composition with the gas phase. In CMAQ v4.7, additional ISORROPIA calls are required during each time step to transfer inorganic gases to and from the coarse mode. In an effort to preserve computational efficiency, coarse-mode mass transfer is skipped when either $\mathrm{RH}<18 \%$ (i.e., the metastable aerosol assumption is questionable) or the summed concentration of coarse $\mathrm{NH} 4, \mathrm{SO} 4, \mathrm{NO} 3$, and $\mathrm{Cl}$ is less than $0.05 \mathrm{ug} / \mathrm{m} 3$ (i.e., coarsemode mass transfer is of negligible importance). Alternatively, users may turn off the coarse-mode mass transfer altogether by setting HYBRID = .FALSE. in the VOLINORG subroutine (line 2827 of aero_subs.f). This is only recommended for model sensitivity studies or for applications in which the inorganic PM composition is of less importance than minimizing model runtime.

In previous versions of CMAQ, ISORROPIA was always run in the 'forward' mode, which partitions total-system concentrations between the gas and particle phases. In CMAQ v4.7, the 'reverse' mode of ISORROPIA is used for the first time. In this mode, vapor pressures of the gas-phase components are predicted based on the particlephase composition, temperature, and $\mathrm{RH}$. These vapor pressures are needed to determine the chemical driving potential between the gas phase and the coarse-particle mode. During testing, we found that ISORROPIA in reverse-mode occasionally returns negative vapor pressures [i.e., variables GAS(1), GAS(2), and/or GAS(3) are less than zero]. A corrected version of ISORROPIA was not available in time for this CMAQ release so, as an interim measure, volatile inorganic species are not transferred to/from the coarse mode during the integration time steps when negative vapor pressures are returned by ISORROPIA and a descriptive warning is written to the log file. 
In previous versions of $C M A Q$, the standard deviation of the coarse-mode particle size distribution was fixed at 2.2, and sulfate was the only condensing component to influence fine-mode standard deviations. In CMAQ v4.7, the standard deviations of all three modes are variable. However, a constraint is imposed such that standard deviations of the accumulation and coarse modes cannot change during the condensation process (see LIMIT_Sg in the GETPAR subroutine, which is contained in the AERO_INFO.f subprogram). This is a temporary patch that was required to achieve a numerically stable solution during dynamic mass transfer, and we hope to relax this constraint in a future public release of CMAQ.

In conjunction with the updated coarse-mode treatment, two new species were added to AE_SPC.EXT: ANH4K and SRFCOR. ANH4K represents the coarse-mode ammonium ion and SRFCOR represents the surface area of coarse-mode particles. All of the AE5 mechanism include files in CMAQv4.7 include these new species. Coarse-mode water $(\mathrm{AH} 2 \mathrm{OK})$ and nitrate $(\mathrm{ANO} 3 \mathrm{~K})$ were included in the $\mathrm{AE} 4$ mechanism files released with previous versions of $C M A Q$, but their concentrations were fixed at zero. In the AE5 module, these concentrations are nonzero. The default boundary concentration profile does not include species commonly associated with sea-salt (e.g., ANAJ, ACLJ, ANAK, ACLK, ASO4K, ANO3K, etc.). For model applications in which one or more of the domain boundaries lies over the ocean, users are urged to add these species to the boundary profile. 